\title{
Comparative study of the impact of COVID 19 and decline in crude oil prices on stock market dynamics
}

\author{
Shruti Singh ${ }^{1^{*}}$ \\ Research Scholar, Dept. of Finance, Institute of Management Studies, Banaras Hindu University, Varanasi, Uttar Pradesh, India \\ *Corresponding Author: Shruti Singh \\ Email: shruti.singh2705@yahoo.com
}

\begin{abstract}
Investors now need a risk-taking approach, and as of May 2020, there is a lot of uncertainty surrounding COVID-19 for investors to predict economic impact, leading to panic and volatility in complete stock market. This study was conducted for a time span of six months (Dec2019-June2020) that tried to evaluate direct and indirect gigantic effect of Corona virus and the crude oil price movements on the financial markets and illustrates how a market is responding to the rapid emergence of a previously abandoned risk. In the past (late February and mid-March), significant price volatility in the stock exchange market is evident and in the aftermath of this inflation outbreak, other patterns in the study have shown strong dependence on stock price volatility in active COVID-19 cases and changes in crude oil prices worldwide.
\end{abstract}

Keywords Financial market, Crude oil, Coronavirus, Pandemic, Aggregate stock price movement.

\section{Introduction}

We are living in an unprecedented time where the data regarding COVID 19 is still emerging and no clear implications or forecasting can be made regarding its influence on the financial markets. The epidemic of the novel corona virus (COVID-19) will go down in history as a major example of a insignificant and neglected risk. A report shared by World Economic Forum's Global Risk Report 2020 (WEF 2020, published on 15 January 2020), the topic "infectious diseases" was ranked tenth in terms of impact but was considered quite dodgy. The attention of corporate and political decision-makers focused exclusively on traditional sources of business risk and showed a keen interest in environmental issues. But the outbreak of the Corona virus caused their attention to change dramatically, just a few weeks later. According to the World Health Organization (WHO), on May 11, 2020, COVID-19 led to more than 4,177,502 confirmed cases of death and 286,330 deaths in 227 countries - and the graph is still growing rapidly. Significant disruptions in people's lives occur, including Lockdowns (or conditions such as the time of homelessness) for too many people. Aside from the imminent catastrophes of death and disease, the unintended consequences for fear hold countless numbers of people worldwide. Moreover especially in the first phase of COVID 19, with the major effect of coronavirus on public and mental health; economic and financial impacts appear to be derived from one another. However, now the economic consequences are probably the most important in the first order. Ultimately, predictions, both in economical and social aspect are difficult to gauge because the tempo of spread of the virus, the course of action taken by the governing bodies, and the individual responses are indefinite and unmapped.
An important tool for understanding the consequences of events like the emergence of COVID-19 and rapid decline in crude oil prices is to consider the volatility encountered in the stock market. These price changes incarcerate present prospects. Effectively, stock markets provide ongoing, highstakes surveys regarding future expected outcomes as a major portion of the economy are driven by these speculation strategies. Earlier this year, many investors expected the 11-year-old bull market to continue in 2020, only to be appalled by the extensive spread of COVID-19. As a result, Sensex is seeing some of the most unexpected features from high-end to market space in just few weeks.

The COVID-19 pandemic can be segregated into three periods, i.e. Endemic, Epidemic, and Pandemic, where the three terms signifies:

1. Endemic: The constant presence of a disease in a population within a certain area.

2. Epidemic: The increase in the number of cases of a disease above what is normally expected in a population in a geographical area.

3. Pandemic: A worldwide spread of a new disease.

In the study we aimed at first examining the stock price reactions to the outbreak of COVID-19 and then stock price reactions to changes in crude oil prices. We further investigate three periods, which we label Endemic (30 December 2019 to 20 January 2020), Epidemic (27 January 2020 to 16 March 2020), and Pandemic (23 March 2020 to at least 11 May 2020) to learn about how the people were responding to the situation by estimating the Search volume index of both the S\&P and the Coronavirus.

\section{Review of Literature}

Many experts have responded to the urgent need to research the impact of COVID-19 on the global economy and global financial markets. Eichenbaum, Rebelo, and Trabandt (2020) used a disease recognition model to study the interaction between economic decisions and epidemics, 
highlighting the inevitable trade between the effects of the temporary economic downturn caused by the epidemic and its health consequences. Ma et al. (2020) compared the global economic and financial outcomes of past epidemics, such as SARS in 2017, H1N1 in 2009, and MERS in 2012, Ebola in 2014, and Zika in 2016, as identified by Jamison et al. (2017). Goodell (2020) discusses the economic and social impact of COVID-19 which has made it similar to previous catastrophic events. Corbet, Hou, Yang, Lucey and Les (2020) analyzed the effects of "coronavirus" on the recovery and behavior of stock stability during the COVID19 epidemic. The results show that companies are showing strong hourly returns and a significant increase in hourly trading volume following the announcement of the COVID19 epidemic. Financial markets under the global COVID19 epidemic have been studied by Dayong Zhang, Min Hu and Qiang Ji (2020). They have tried to map common patterns of global risks and systemic risks in global financial markets. It also analyzes the potential impact of policy interventions, such as the US decision to use zero interest rates and unlimited quantitative (QE) reductions, and to what extent these policies could bring uncertainty to global financial markets. The aviation industry in the financial security market during the COVID-19 crisis was analyzed by Conlon and McGee (2020), as well as Corbet, Larkin, and Luky (2020) in terms of gold and crypto currencies, which provide consistent evidence that Bitcoin does not provide a safe or secure environment with the COV epidemic. 19. Also, Arshian Sharif, Chakari Aloui and Larisa Yarovaya (2020) conducted research on the COVID-19 epidemic, oil prices, stock market, political risks and policy uncertainty in the US economy: New evidence from the wave process, where they analyzed the links between the recent spread of COVID-19, oil price shocks, the stock market, political risks and uncertainty of US economic policy within the framework of the frequent frequency. In addition, Yarovaya, Matkovskyy, and Jalan (2020) analyzed financial market monitoring during the COVID-19 epidemic, which reported that monitoring remained based on marketing days or less, but was not robust during COVID-19. Yarovaya, Brzeszczynski, Goodell, Lucery, and Lau, (2020) discuss the various symptoms of the COVID-19 problem in comparison with previous disaster episodes and provide indications for future research.

\section{Research Method \\ Data}

The first source of data contains information on price returns of the BSE market, with weekly resolution. For each week we extract the opening price, closing price and the volume traded on BSE, both in Indian markets as well as World market. The S\&P data is collected on weekly basis for six months, i.e. from $20^{\text {th }}$ January 2020 to $22^{\text {nd }}$ June 2020. Similarly the crude oil prices are also collected using the same source for the above mentioned time frame. These data are publicly available and can be downloaded from various sources on the Internet. The data for this study is extracted from Yahoo! Finance.
The data for COVID-19 cases in India and world is collected from various sources on internet some of them being the reports presented by GOI and world data from various news portals.

\section{Data analysis model}

For data analysis two tools are used:

1. Google Search Intensity(SVI) using Google Trends

2. Linear Regression Analysis using SPSS

\section{Findings}

1. Google Search Intensity(SVI) using Google Trends The events initiating the Epidemic and Pandemic periods markedly changed the attention of market participants. It can be traced from the Search Volume Index that the proportion of firms discussing these topics increased dramatically over time, to about $30 \%$ at the beginning of the Epidemic period. When the Pandemic period began, that fraction increased to about $65 \%$.

\section{SVI on Coronavirus}

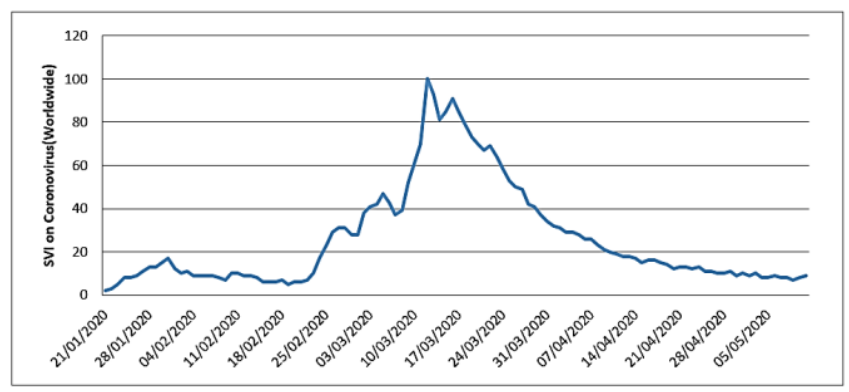

The global Google search intensity on coronavirus increased massively after 20 January. It subsided somewhat after its interim peak at the end of January, but when the Epidemic period started, the search intensity spiked.

\section{SVI on BSE and Sensex}

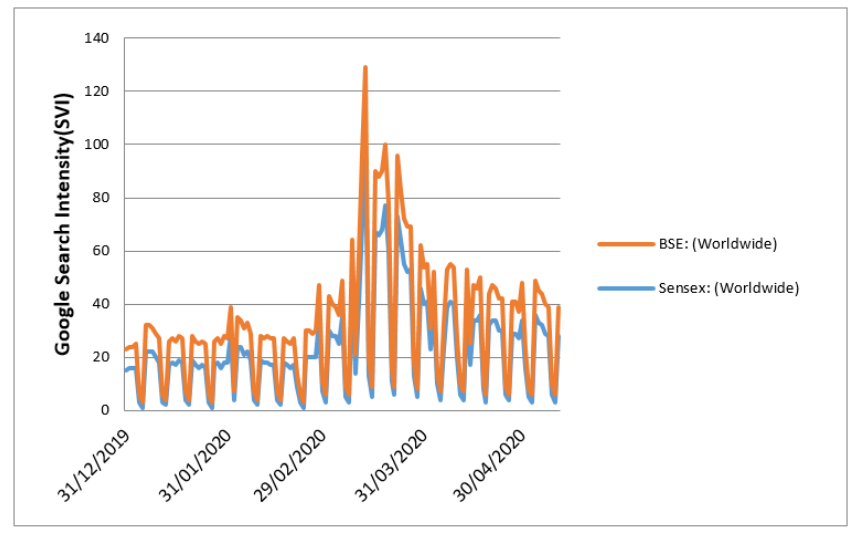




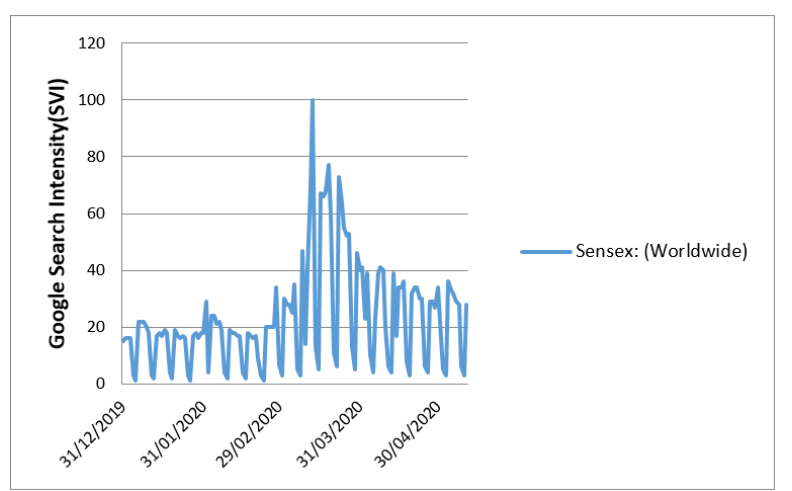

Similarly, Search Volume Index on Sensex and BSE increased massively after $30^{\text {th }}$ January. It was sluggish somewhat after its interim peak at the end of February, but when the Epidemic period started, the search intensity spiked.

\section{SVI on crude oil prices}

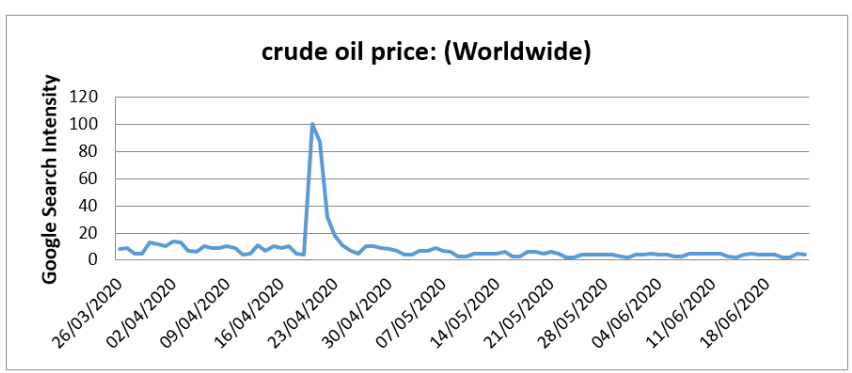

The Search Volume Index of crude oil prices rose sharply after April 16 worldwide, following a dispute between Saudi Arabia and Russia over oil cuts that created a "complete storm" on oil prices, exacerbating the situation. The Saudis have decided to increase oil production to more than 10 million barrels a day, despite lower prices, and consolidate their position in the global industry. Moreover, the statistical trend of stock market movements clearly indicates impact of COVID19 and crude oil price fall on the volume being traded and the S\&P price index. As represented graphically, it can be observed that as soon as the number of cases started rising the Sensex saw hike in its price which gradually declined as investors started anticipating the risk aspect of investing in Stock market.

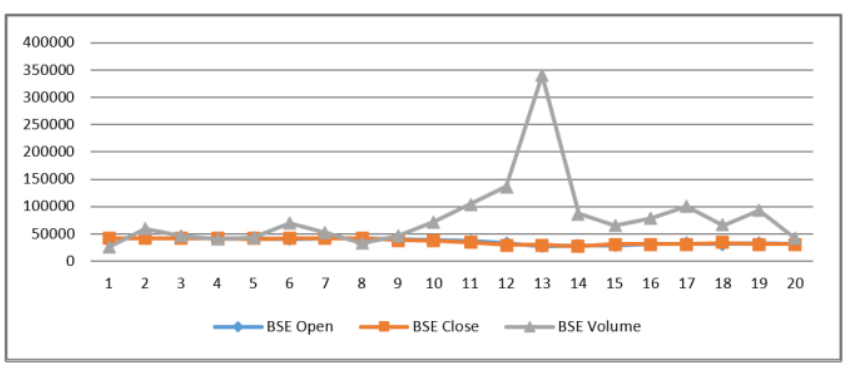

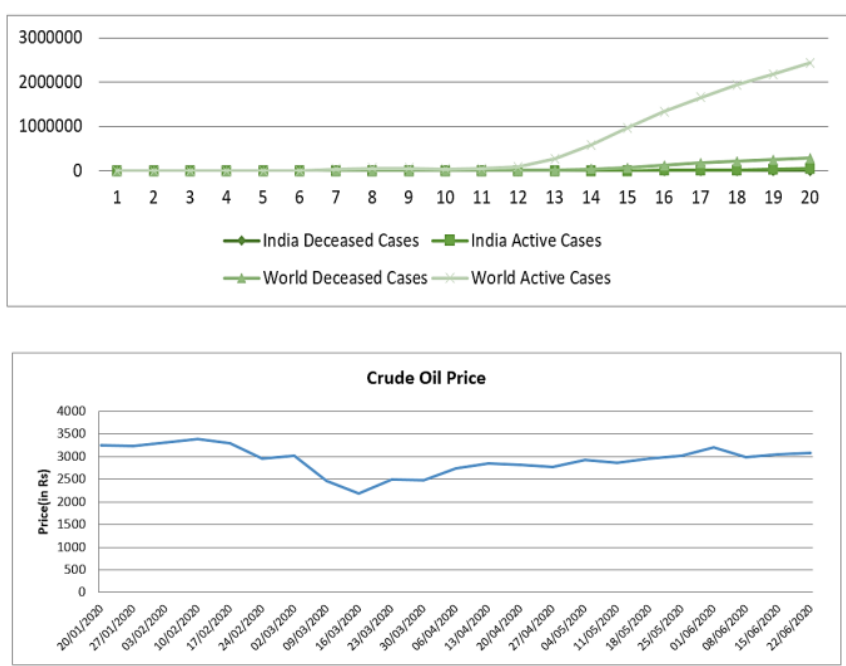

\section{Linear regression analysis using SPSS}

The linear regression analysis is used to cart the study of estimating the impact of the virus and the fall in the crude oil price on the stock market movement.

The variables used are-

a) Dependent Variable- S\&P price index

b) Independent Variable- Crude oil price/barrel, number of active cases in India and World.

\begin{tabular}{|l|l|c|c|}
\hline \multicolumn{4}{|c|}{ Variables Entered/Removed } \\
\hline Model & \multicolumn{1}{|c|}{ Variables Entered } & $\begin{array}{l}\text { Variables } \\
\text { Removed }\end{array}$ & Method \\
\hline 1 & $\begin{array}{l}\text { World Active Cases, } \\
\text { Crude Oil, India Active } \\
\text { Cases }^{\mathrm{a}}\end{array}$ & $\cdot$ & Enter \\
\hline \multicolumn{2}{|l|}{ a. All requested variables entered. } & \\
\hline
\end{tabular}

The linear regression model fit summary is shown below:

\begin{tabular}{|l|c|c|c|c|c|}
\hline \multicolumn{7}{|c|}{ Model Summary } \\
\hline Model & $\mathrm{R}$ & $\begin{array}{c}\mathrm{R} \\
\text { Square }\end{array}$ & $\begin{array}{c}\text { Adjusted } \\
\mathrm{R} \text { Square }\end{array}$ & $\begin{array}{c}\text { Std. Error of } \\
\text { the Estimate }\end{array}$ & $\begin{array}{c}\text { Durbin- } \\
\text { Watson }\end{array}$ \\
\hline 1 & $.917^{\mathrm{a}}$ & .841 & .816 & 5.15598 & 1.668 \\
\hline
\end{tabular}

As $\mathrm{R}$ Square value is 0.841 which denotes that $\mathrm{S} \& \mathrm{P}$ prices depend highly $(84.1 \%)$ on the crude oil price movement and the number of cases hit by the coronavirus. Moreover, the Durbin Watson (DW) statistic is a test for autocorrelation in the residuals from a statistical regression analysis. The Durbin-Watson statistic always has a value between 0 and 4 . A value of 2 means that there is no autocorrelation detected in the sample. Values from 0 to less than 2 indicate positive autocorrelation and values from 2 to 4 indicate negative autocorrelation. Durbin-Watson in this study turns out to be 1.668 less than 2.0 indicating a certain degree of autocorrelation present because stock prices tend to fluctuate significantly from one day to the next, prices from one day to the next may be highly correlated. The stock price indicator for autocorrelation will indicate that the price yesterday had a positive correlation on the price today - so if the stock fell yesterday; it may also fall today. 


\begin{tabular}{|c|c|c|c|c|c|c|}
\hline & & & efficients ${ }^{a}$ & & & \\
\hline & & Unstandar & Doefficients & Standardized & $\mathrm{t}$ & Sig. \\
\hline & & B & Std. Error & Beta & & \\
\hline 1 & (Constant) & -40.825 & 11.123 & & -3.670 & .002 \\
\hline & Crude Oil & .028 & .004 & .703 & 7.379 & .000 \\
\hline & India Active Cases & .000 & .000 & .928 & 4.314 & .000 \\
\hline & World Active Cases & $-9.818 \mathrm{E}-6$ & .000 & -1.112 & -5.261 & .000 \\
\hline
\end{tabular}

The coefficient part of the result shows that beta for variables "Crude Oil prices" and "active cases in India" comes out to be .703 and .928 respectively which shows for 1 unit change in "Crude oil prices", "Count of active cases in India" changes by .703 and same changes by .928 if change is 1 unit in variable "S\&P Price index". This shows that the movement in stock market is dependent highly on both the crude oil prices and the covid19 active cases in India. However, the statistics shows the independence of $\mathrm{S} \& \mathrm{P}$ on the total active cases across the world as the beta comes out to be -1.112 .

The shape of the histogram follows the shape of the normal curve fairly well, but there are one or two large negative residuals.
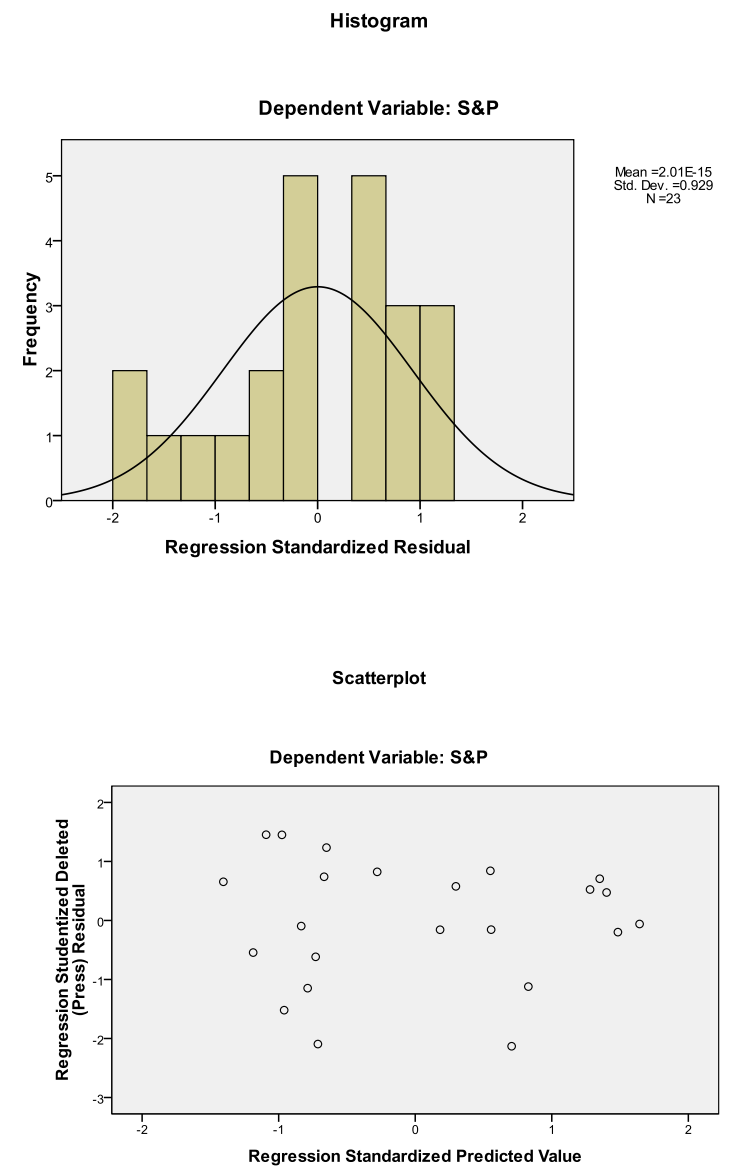

\section{Conclusion}

The investor's sentiments in the stock markets across the world are ominous. This is reflected in the frequent crashes in the share markets in all parts of the world. Financial markets in India are witnessing sharp volatility currently as a result of the fallout in Indian as well as global markets. The three periods identified in this study i.e. Endemic, Epidemic and Pandemic showcase some patterns, which showed that investors were instigated and were concerned with the amplification of the Covid-19. The fall is in line with global equity indicators as the domestic market is often following major global indicators and high volatility is likely to continue soon. Overall, this study shows how the market responds to the rapid emergence of a previously abandoned risk. In the most recent period (late February and mid-March), a significant price movement in the stock market is being observed. The spread of this terrible disease is contributing to the global economic downturn, making the threat of a global recession less visible. Another, perhaps the biggest, driver of the stock market crash on March 9, 2020, was the oil price war that erupted just days before the event. Related to the virus, there has been a recent decline in oil demand, which has reduced its price. Factories have been idle and thousands of flights have been cancelled since the outbreak became a global epidemic. In the meantime, it is too early to say whether the worst has passed as the daily fluctuations of the market make it difficult to identify a clear trend. The combination of the virus, the crude oil price decline and huge drop of stock prices may cause a wealth effect.

\section{Source of Funding \\ None.}

\section{Conflict of Interest}

The authors declare no conflict of interest.

\section{References}

1. Zhang D, Hu M, Ji Q. Financial markets under the global pandemic of COVID19. Retrieved 10 June 2020, from https://www.sciencedirect.com/science/article/pii/S154461232 0304050.

2. Sharif A, Aloui C, Yarovaya L. COVID-19 pandemic, oil prices, stock market, geopolitical risk and policy uncertainty nexus in the US economy: Fresh evidence from the waveletbased approach. Retrieved 4 June 2020, from https://www.sciencedirect.com/science/article/pii/S105752192 030140X. 
3. Ashraf B. Economic impact of government interventions during the COVID-19 pandemic: International evidence from financial markets. Retrieved 17 June 2020, from https://www.sciencedirect.com/science/article/pii/S221463502 0302422 .

4. Ashraf B. Stock markets' reaction to COVID-19: Cases or fatalities?. Retrieved 26 May 2020, from
https://www.sciencedirect.com/science/article/pii/S027553192 0304141.

How to cite this article: Singh S. Comparative study of the impact of COVID 19 and decline in crude oil prices on stock market dynamics. $J$ Manag Res Anal. 2020;7(4):142-6. 